\title{
Social integration and dialect divergence in coastal Palestine ${ }^{1}$
}

\author{
William M. Cotter and Uri Horesh \\ University of Arizona and Northwestern University, Illinois, U.S.A.
}

The history of Palestine has caused communities to be displaced and relocated, entailing that speech communities have been dismantled and created anew. The coastal cities of Jaffa and Gaza exemplify this reality. This study analyzes speakers from Jaffa, some of whom remained there and others residing in Gaza as refugees. Through an examination of three variables, $(\mathrm{S}),(\mathrm{AH})$, and $(\mathrm{Q})$, we shed light on the effects of dialect contact while highlighting the link between dialect contact and identity formation and maintenance. All three variables are found to be in varied states of change as a result of contact with other varieties of Arabic, as well as with Modern Hebrew. We conclude that (Q), through its high social salience, works to create and maintain a sense of community identity for Jaffan refugees in Gaza at a time when the speech of the larger Jaffa community is undergoing substantial linguistic change.

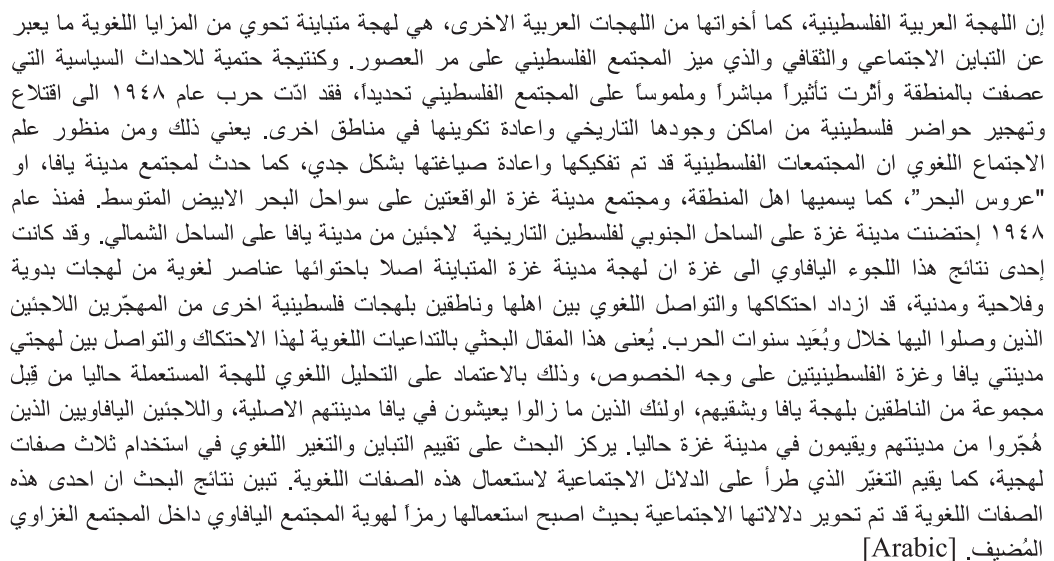

KEYWORDS: Palestinian, Arabic, language variation, Jaffa, Gaza, identity 


\section{INTRODUCTION}

\section{Overview}

The sociolinguistics of Arabic varieties is much more complex than the conventional nomenclature of Arabic dialects may lead the non-specialist to believe. One hears or reads of linguistic entities such as 'Egyptian Arabic,' 'Syrian Arabic,' 'Moroccan Arabic,' which imply that each of these is a singular, cohesive unit, which one can describe, study, and become proficient in. Furthermore, these nation-state-based labels create the illusion that today's political borders, many of which are artificial colonial or post-colonial creations of the early-to-mid 20th century, are able not only to each contain a single dialect of Arabic, but also delimit the beginnings and endings of dialect areas, as if political events are the sole factors in the formation of isoglosses.

Compare Arabic to another well-studied language, e.g. English, and it becomes clear. While in some instances it may be useful to distinguish 'British English' from 'American English' from 'Canadian English' and so forth, the multitude of sociolinguistic studies now at our disposal from each of these countries demonstrates just how limited these taxonomies are. Add to that regional, social, interpersonal and intrapersonal variation, and - most importantly to the case we shall be presenting henceforth - migration, isolation, and dialect contact and it will become clear that in Arabic, as in other languages, a fine-tuning of our understanding and a definition of dialect boundaries is in order.

The current study concerns a Palestinian speech community. This community can, actually, be viewed as two communities which have split from one another as a result of ethnic cleansing and displacement and subsequent immersion in a third community. More specifically, the city of Jaffa, on the Mediterranean coast of central Palestine, which had been a thriving cultural, intellectual and economic urban center of the Arab Palestinian community (LeVine 2005), was brutally emptied of over 90 percent of its inhabitants in 1948 during the 'Catastrophe' (Nakba in Arabic), the Zionistpropagated ethnic cleansing of Palestine, which led to the establishment of the Jewish-majority State of Israel. The 90+ percent of Jaffa residents who were driven out of the city became refugees, many of whom fled to Gaza, some 69 kilometers south of Jaffa, on the same Mediterranean coast (LeVine 2005; Morris 2008; Pappé 2006).

Being a refugee in Gaza carries some degree of social markedness, as well as the refugee status that most speakers are afforded by the United Nations. Part of this social markedness has to do with dialect differences. The traditional dialect of Jaffa differs from that of Gaza in a number of interesting ways. This is one prime example of two dialects, both urban, both Palestinian, both coastalMediterranean - three features which are known in Arabic dialectology to 
indicate convergence of dialectal features - which have nonetheless diverging features, as we will demonstrate below.

Our analysis provides an examination of the linguistic outcomes of politically induced and maintained dialect contact in one of the world's most volatile areas. At the same time, we suggest that a sociolinguistic variable of high social salience in the Arabic speaking world is being re-contextualized as an identity marker in Gaza City. What may once have been considered a variable split along fairly straightforward sociolinguistic lines has taken on new meaning in Gaza City to create and maintain identity within a community of Jaffan refugees now living in the coastal strip.

As Bucholtz and Hall (2004: 371) have argued, the systemic organization of difference, which is in our specific case, linguistic difference, is an output of identity work. At the same time identity, particularly ethnic, often emerges in cases of contact and allows communities and individuals to avoid the 'de-ethnicizing process of citizenship in the nation-state' (Bucholtz and Hall 2004: 371; also see Fishman 1999). While it is true that Palestine does not today constitute a full-fledged nation-state, it is impossible to deny that some wider conceptualization of Palestinian identity does exist. However, this larger sense of identity is intertwined with hyper-localized identity frames tied to specific geographic locations, many of which have been physically erased as a result of forced migration.

By examining the outcomes of dialect contact we show how the enduring relationship between sense of self and specific, localized, community affiliations within the Palestinian community can be viewed linguistically. We argue that by viewing the linguistic practices of Jaffan refugees in Gaza City it is possible to highlight the wider social implications of dialect change as a result of contact in coastal Palestine. Following a discussion of the corpus that constitutes the data of the study, we describe and analyze the three sociolinguistic variables under investigation. Based on the results to be detailed below, our analysis then focuses its attention more directly on the final variable whose variants, we argue, index (Eckert 2008; Silverstein 2003) different aspects of community identity in Gaza and Palestine more generally.

\section{The corpus}

During a window of relative political and military calm, Cotter (2013) was able to obtain the necessary authorization to enter Gaza through Egypt for a period of four weeks and conduct fieldwork. In May 2013, he interviewed 39 speakers in Gaza. Of this sample, 32 speakers are from families that trace their history back to Gaza City, while the remaining seven speakers are refugees from Jaffa, part of a larger community of refugees from throughout historic Palestine that today make up more than 70 percent of the population of the Gaza Strip. ${ }^{2}$ Within this 'refugee' group we include both persons who were born in Jaffa 
before 1948 and expelled during its ethnic cleansing (two out of the seven) and their offspring who were born in Gaza (the remaining five). Horesh conducted fieldwork in Jaffa in 1999, 2004 and 2005, having interviewed 24 native speakers of the Jaffa dialect (23 of them in Jaffa proper, one in the village of Jaljulya, where one of the speakers had been internally displaced). Those speakers remaining in Jaffa are today the minority, with only 16,000 Palestinians still living in the Tel Aviv-Jaffa metropolitan area, which has a population of over $400,000 .^{3}$ Twelve additional speakers were interviewed by Horesh in the West Bank cities of Ramallah and Jerusalem for comparison. In all cases, the data are derived from sociolinguistic interviews conducted by the authors with local speakers in or near their places of dwelling or employment. All interviews were recorded digitally, saved and backed up in several locations.

The current study is based on subsets of the samples from Horesh's Jaffa study and Cotter's Gaza study, constructed in a manner that allows for a preliminary understanding of the evolution of the Jaffa dialect over time and space. For this purpose, we extracted the seven speakers from the Gaza sample who were either born in Jaffa or were of Jaffa ancestry and identified as refugees from Jaffa (henceforth 'Gaza speakers'). We supplemented the corpus with data from seven speakers from the Jaffa sample (henceforth 'Jaffa speakers'). The speakers chosen from the Jaffa sample were each as close as possible in year of birth and of the same gender as one of the Gaza speakers, thus creating a relatively balanced sub-corpus.

The speakers seen in Table 1 can be classified in the following manner:

1. Six speakers born in Jaffa who have remained Jaffa residents.

2. One speaker who was born in Jaffa and left in 1946 to marry, then displaced in 1948 and eventually resettled in a village near the border between modern-day Israel and the West Bank (on the Israeli side).

3. Two speakers who were born in Jaffa and were expelled to Gaza in 1948.

4. Five descendants of Jaffa-born Palestinians who were born in Gaza: two children of Jaffa natives and three grandchildren.

It may be argued that the speakers in (4) above should not be included in a study such as this. After all, they have spent their entire lives in Gaza, and report never having visited their ancestral town of Jaffa. Yet the social structure in Gaza is such that these speakers are still marked, both linguistically and socially, as refugees, and they very much identify with their Jaffa heritage. Among other things, this identification with Jaffa is a reminder to themselves and to their interlocutors that they are victims of the violence that had erupted in 1948. This situation is analogous to some extent with the situation described by Mesthrie regarding Indians living in South Africa under Apartheid. In the 1960s, Mesthrie (2007: 148) reports: 'Young speakers losing touch with their ancestral languages did not think of themselves as any less “Indian.”' Similarly, in Gaza, Jaffan Palestinians who 
Table 1: Demographics of the combined sample of residents of Jaffa and Jaffa refugees living in Gaza City $(\mathrm{f}=$ female; $\mathrm{m}=$ male)

\begin{tabular}{lccc}
\hline Pseudonym & Year of birth & Sex & City \\
\hline Umm Khalil & 1928 & $\mathrm{f}$ & Jaffa \\
Dina & 1933 & $\mathrm{f}$ & Gaza \\
Bianca & 1935 & $\mathrm{f}$ & Jaffa \\
Layla & 1943 & $\mathrm{f}$ & Gaza \\
Maryam & 1990 & $\mathrm{f}$ & Jaffa \\
Sabihah & 1993 & $\mathrm{f}$ & Gaza \\
Salem & 1948 & $\mathrm{~m}$ & Jaffa \\
Ahmad & 1956 & $\mathrm{~m}$ & Gaza \\
Sabeer & 1960 & $\mathrm{~m}$ & Gaza \\
Yazid & 1971 & $\mathrm{~m}$ & Jaffa \\
Jamil & 1981 & $\mathrm{~m}$ & Jaffa \\
Tamim & 1983 & $\mathrm{~m}$ & Gaza \\
Wajdi & 1985 & $\mathrm{~m}$ & Gaza \\
Tariq & 1987 & $\mathrm{~m}$ & Jaffa \\
\hline
\end{tabular}

have lived their entire lives as refugees still maintain a direct link to their heritage not only through social and cultural ties that transcend geopolitical boundaries, but also, as we argue below, in their linguistic practices.

The analysis that follows aims to investigate three features which appear to have emerged as sociolinguistic variables in urban Palestinian Arabic. These variables are provided in Table 2 alongside the variants that are typical of the dialects of Jaffa and Gaza respectively, as well as examples of the variation that is present in the data. Following our analysis of these variables in light of dialect contact, we move on in the discussion to look at the broader social and identity-based implications of this type of linguistic contact.

Table 2: Realization of the variables $(\mathrm{Q}),(\mathrm{AH})$, and ( $\mathrm{(})$ in the speech of residents of Jaffa and refugees of Jaffa heritage in the Gaza Strip

\begin{tabular}{lllll}
\hline Variable & $\begin{array}{c}\text { Variants in } \\
\text { the Gaza } \\
\text { dialect }\end{array}$ & $\begin{array}{c}\text { Variants in } \\
\text { the Jaffa } \\
\text { dialect }\end{array}$ & $\begin{array}{c}\text { Examples of } \\
\text { alternations } \\
\text { in Gaza City }\end{array}$ & Gloss \\
\hline$(\mathrm{Q})$ & {$[\mathrm{g}] \sim[\mathrm{P}]$} & {$[\mathrm{P}]$} & gahwa $\sim$ Pahwa & 'coffee' \\
$(\mathrm{AH})$ & {$[\mathrm{a}] \sim[\mathrm{e}]$} & {$[\mathrm{e}]$} & hilwa $\sim$ hilwe & 'pretty' \\
$(\mathrm{S})$ & {$[\mathrm{S}] \sim[\mathrm{P}]$} & {$[\mathrm{S}] \sim[\mathrm{P}]$} & baSde:n $\sim$ ba?de:n & 'afterwards' \\
& $\sim[\mathrm{V}:][\mathrm{V} . \mathrm{V}]$ & $\sim[\mathrm{V}:] \sim[\mathrm{V} . \mathrm{V}]$ & $\begin{array}{l}\sim \text { ba:de:n } \sim \text { ba.a.de:n } \\
\sim \text { bade:n }\end{array}$ & \\
& $\sim \varnothing$ & $\sim \varnothing$ &
\end{tabular}




\section{LENITION OF THE VOICED PHARYNGEAL FRICATIVE (९)}

\section{History of the variable}

A purely phonological variable, the traditional voiced pharyngeal fricative / $/$ / is simultaneously a quintessential characteristic of virtually all varieties of Arabic (the main exception is Maltese) and one of the most vulnerable phonemes in the language. This is perhaps because of its rareness amongst the languages of the world, its articulatorily expensive production and its nearvocalic acoustic nature. In Horesh (2014), quantitative evidence shows that in the contemporary Jaffa speech community, there is a tendency to lenite this phoneme in casual speech to [?], $\varnothing$ or one of several vocalic realizations, and that this tendency is correlated with speakers' contact with Modern Hebrew. This is in contrast to the results of lenition reported by Horesh (2014) for a control group of speakers in the West Bank cities of Jerusalem and Ramallah, who not only lenite (؟) much less frequently but also have much lower rates of contact with Modern Hebrew.

Hebrew underwent a massive reduction of its phonemic inventory beginning in the late 19th century, when it was 'revived' using a phonemic system similar to a number of European languages (the most notable of these being Yiddish; see Wexler 1990; Zuckermann 2003) that lack the historic Semitic phonemes: pharyngeal consonants, emphatic consonants, uvular stops. This reduction in the Hebrew phonemic inventory has had a contact effect on the Arabic spoken by Palestinian citizens of Israel (such as those who remained in Jaffa). The lenition of $/ \mathrm{S} /$ is one consequence of this contact.

In order to ascertain to what extent, if any, (§) is lenited in the speech of indigenous Gazan speakers, we sampled five speakers of both genders and various age groups from the larger corpus collected by Cotter (2013). The degree of lenition was found to be on average less than 10 percent of the tokens sampled (mostly in a limited set of lexical items, namely the discourse marker jasni 'that is' and numerals with an intervocalic / ///). The rate of complete deletion of the voiced pharyngeal fricative was close to zero. The only speakers in this subset who showed somewhat more frequent lenition of (S) in their speech were two middle-aged men, who in the course of their interviews revealed that they had been imprisoned inside Israel for prolonged amounts of time. As a result they not only had more exposure to Hebrew through their interactions with prison officials, but also acquired limited knowledge of spoken Hebrew. In order to avoid a skewing of the data, these two speakers were excluded from the analysis.

This suggests that, in terms of contact with Hebrew, the Gaza speech community is even more isolated than those communities examined in the West Bank. Contact with Hebrew is virtually non-existent for the vast majority of Gaza residents and lenition of $(\mathrm{C})$ as a result of contact plays a more limited role than it does in the Jaffa case. Even the older Gaza speakers in our sample, who were born in Jaffa, are not expected to have had significant contact with 
Hebrew, as they were all displaced from Jaffa prior to the city becoming bilingual and prior to the introduction of Hebrew instruction in its schools.

\section{(५) results}

Horesh (2014) established that at least five variants of the (\$) variable are in play:

1. Voiced pharyngeal fricative $[\mathrm{C}]-$ /arbaৎa/ $\equiv$ [arbaৎa] 'four.'

2. Glottal stop [?] - /se:Sa/ [se:?a] 'hour.'

3. Syllabic vocalization, i.e. two vowels, whether identical or not, separated by a syllable boundary - V.V - /maw.d` u:S/ [maw.d' $\mathrm{d}: . a]$ 'subject.'

4. Compensatory lengthening of an adjacent vowel $-\mathrm{V}:-/$ maSru:f/ [ma:ru:f] 'known.'

5. Deletion $-\varnothing-/$ m Gallmi:n/ $\sim$ [malmi:n] 'teachers. ${ }^{4}$

Upon running both linear and logical regressions using Rbrul (Johnson 2009) with various combinations of the Jaffa and Jaffa+West Bank data, it became evident that the phonetic distinctions among variants (2)-(5) above do not contribute much to the analysis. For our current study, therefore, we only considered a binary model of variable rule analysis, whereby any value greater than one would be considered an application of the variable rule lenition, and one would be considered non-application.

In the initial run of the combined data coded for Jaffa and Gaza speakers, we considered Speaker as a 'random effects' factor group. While the regression found this factor group to be significant, there was little, if any, other advantage to continue including Speaker in any further analysis, as no specific speaker proved to have any meaningful influence on the results as a whole, and in fact caused other, 'real' social factors, to be thrown out. In other words, while the factor group was found to be significant against other factor groups, no individual speaker stood out, and no particular patterning of speakers could be discerned within this factor group. This finding was the same across all three variables analyzed and as a result we have removed Speaker as a 'random effects' group from all of the results that we discuss in this study.

The results for the Community factor group (Table 3) are fairly straightforward and further confirm the hypothesis that contact with

Table 3: Lenition of $(\mathcal{S})$ in the combined sample of Jaffa residents and refugees of Jaffa heritage living in Gaza City correlated with Community $\left(\mathrm{R}^{2}=0.051\right.$; $\mathrm{p}=7.35 \mathrm{e}-07$ )

\begin{tabular}{lcrr}
\hline Community & \% lenition & Logodds & Tokens \\
\hline Jaffa & 63 & 0.381 & 351 \\
Gaza & 46 & -0.381 & 358 \\
\hline
\end{tabular}


Table 4: Lenition of (؟) in the combined sample of Jaffa residents and refugees of Jaffa heritage living in Gaza City correlated with Year of Birth $\left(\mathrm{R}^{2}=0.051\right.$; $\mathrm{p}=0.0273$ )

\begin{tabular}{lccr}
\hline Year of Birth & \% lenition & Logodds & Tokens \\
\hline Before 1948 & 60 & 0.011 & 221 \\
$1948-1973$ & 54 & 0.246 & 210 \\
1974 and after & 50 & -0.256 & 278 \\
\hline
\end{tabular}

Hebrew contributes to the favoring of lenition of the voiced pharyngeal fricative. The speakers who remained in Jaffa and now live alongside Hebrew speakers, have been exposed to a complex system of education, government, commerce and administration in Hebrew. They are, in fact, for the most part, fully bilingual, with many current-day Jaffans attesting that they feel more comfortable speaking, reading, writing and doing business in Hebrew than in Arabic. And it is this group of speakers within Jaffa that shows the higher tendency to pronounce a lenited (§). These results for the lenition of (؟) in the speech of Jaffa speakers contrasts not only the speech of the Gaza speakers in the sample, but also those West Bank speakers initially examined in Horesh (2014) who showed lower rates of lenition compared to their Jaffa counterparts.

Looking at Year of Birth (Table 4) as a significant factor, a more nuanced explanation may be in order. One may be surprised to find that the youngest group of speakers is the least advanced in what appears to be a change in progress in the Jaffa dialect. However, two things must be taken into account. First, Horesh (2014) has found that even in Jaffa alone the youngest group of speakers was one of the groups least prone to lenition of (C), noted in Table 5. This stems from the inclusion in this group of both very young (high schoolaged) speakers and older speakers, in a manner in which the high-schoolers did not dominate the group. Indeed, when the youngest speakers, high school students, were singled out for investigation, they were found to be favoring lenition, as shown in Table 6.

Secondly, the youngest group of speakers in the Gaza subset of our sample are probably best characterized for the sake of this study not merely as young and therefore expected to be innovative linguistically - but as the most

Table 5: Deletion of $(\mathrm{S})$ in the speech of Jaffa residents correlated with Age $\left(\mathrm{R}^{2}=0.272 ; \mathrm{p}<0.05\right)$ (from Horesh 2014)

\begin{tabular}{lccc}
\hline Age & \% deletion & Logodds & Tokens \\
\hline $14-35$ & 44 & -0.024 & 290 \\
$36-60$ & 38 & 0.365 & 798 \\
$61+$ & 21 & -0.341 & 322 \\
\hline
\end{tabular}


Table 6: Deletion of ( $($ ) in the speech of Jaffa residents correlated with Occupational Group $\left(\mathrm{R}^{2}=0.272\right.$; $\left.\mathrm{p}<10 \mathrm{e}-10\right)$ (from Horesh 2014)

\begin{tabular}{lccc}
\hline Occupational Group & \% deletion & Logodds & Tokens \\
\hline Teenager & 40 & 0.858 & 336 \\
Blue collar & 30 & 0.076 & 307 \\
Service & 53 & -0.144 & 72 \\
White collar & 38 & -0.791 & 705 \\
\hline
\end{tabular}

removed from life in Jaffa, among speakers of the Jaffa dialect. This is because they were born or brought up following the first Palestinian intifada 'uprising' of 1987 and have had very little, if any, opportunity to leave the Gaza Strip because of restrictions imposed by the Israeli government. This permits us to formulate two, perhaps complementary, propositions:

1. Lenition of the voiced pharyngeal fricative, as a variable rule, is inherent to the Jaffa dialect, regardless of contact with Hebrew, more than it is for the Gaza dialect.

2. Since we know that contact with Hebrew is a salient factor in Palestinian Arabic (Hawker 2013; Henkin-Roitfarb 2011; Horesh 2014), extreme lack of contact amongst half of this younger combined group - those in Gaza - is yet another contributing factor to the results presented above.

In this respect, lenition of (؟) appears to be happening to a much greater extent within the speech of those speakers who have remained in Jaffa, with Gaza speakers leniting much less frequently. The result for Gaza speakers reflects that their speech has diverged from what is today the norm in the Jaffa dialect. In a similar fashion for the remaining two variables, we see additional instances of Gaza speakers diverging from the Jaffa dialect, while converging towards local Gazan linguistic norms.

\section{THE FEMININE GENDER MARKER $(\mathrm{AH})^{5}$}

\section{History of the variable}

This variable, which pertains to a specific Arabic morpheme, is phonologically conditioned. Through an examination of earlier descriptive work, it is possible to posit a foundational description of the conditioning environments for vowel raising of the feminine marker (Grotzfeld 1980; Levin 1994; Versteegh 2001). With respect to general processes of vowel raising (ima:la in Arabic) in Levantine dialects (e.g. Palestinian, Syrian, Lebanese), the following rules have been posited (see Al-Wer 2007: 68; Grotzfeld 1980: 181; Levin 1994: 44-45): 
1. The default vowel of the feminine ending is $-e-$ the 'raised' variant. ${ }^{6}$

2. The vowel of this ending is $-a$ in the following cases:

a. after 'back' consonants (i.e. pharyngeal, glottal, 'emphatic'/

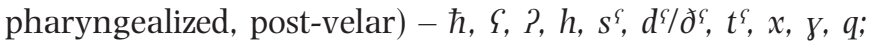

b. after $r$, but only if preceding the $r$ there is no high front vowel. This is true both for words with a synchronic i(:) vowel before $r$ or, in some cases, if there is a historic $i$ vowel before the $r$ which had been deleted due to a process in many of these dialects whereby short vowels in unstressed syllables tend to delete. In the latter case, there is usually variation between $-a$ and $-e$ as the feminine ending vowel (e.g. n-na:s'ra n-na:s're [< n-na:s'ira], 'Nazareth').

Raising of the feminine marker has been attested in most of the major urban centers throughout the Levant and is a dialect feature often associated with the dialects of the major Levantine capitals. This type of raising has been described linguistically for the cases of Jerusalem (Levin 1994; Rosenhouse 2007), Amman (Al-Wer 2007), Damascus (Lentin 2007), and Beirut (Naïm 2007), among others. This distinguishes Levantine urban dialects from other areas, notably Cairo (Woidich 2007), which do not raise the feminine marker, leaving its realization in the neighborhood of [a].

In the case of Gaza City, the present home of the Jaffa refugees included in this study, treatment of the feminine marker is limited to the two primary sources available on the dialect, Bergsträßer (1915) and Salonen (1979, 1980). Bergsträßer's early dialect atlas details no raising of the feminine marker in Gaza City (Bergsträßer 1915: map 6). In contrast to Bergsträßer's account, Salonen's $(1979,1980)$ texts do suggest some degree of raising for this feature. This raising manifests with the vowel in question being raised from [a] to [e], and also as high as [i] in certain examples (Salonen 1979: 40). However, most of Salonen's informants were not actually from Gaza City itself, but from the surrounding rural area (de Jong 2000: ch. 5, see comment 8). In addition to these two earlier dialectological works, a series of texts from Gaza collected by Barnea (1973) is available. Examples provided in Barnea (1975:4) show variable raising of the feminine marker, but a closer examination of Barnea's data reflects that on the whole the texts present limited instances of raising.

Barnea's $(1973,1975)$ findings are supported by the more recent fieldwork conducted by Cotter (2013). As Cotter's work reflects, the indigenous dialect of Gaza City does not raise this vowel, realizing it categorically as [a], suggesting that for speakers who are not of a refugee background $(\mathrm{AH})$ is not a linguistic variable at all. This provides us with a baseline by which to judge the degree to which Jaffa refugees in Gaza City have converged towards local norms for $(\mathrm{AH})$.

In contrast to the Gaza case, when examining the linguistic information available on the dialect of Jaffa (e.g. Al-Wer 2007: 68-71), [e] emerges as the default variant of $(\mathrm{AH})$ with [a] appearing in specific phonological environments, as described earlier. At the regional level, Al-Wer notes, in 
general, the non-raising dialects are generally peripheral, localized, non-urban dialects, whereas all of the socially dominant dialects are raising dialects, such as the dialects of Beirut, Damascus, and Jerusalem' (Al-Wer 2002: 71). The dialect of Gaza City, therefore, can be viewed as a more peripheral dialect. Despite this, in reality, the dialect situation of Gaza City is more complex, as it utilizes a collection of both urban and Bedouin linguistic features (see De Jong 2000: ch. 5 for more details). In light of Al-Wer's discussion on the phonological conditions which favor raising in urban Palestinian Arabic, we would expect a scenario in which speakers of a Jaffa dialect background would raise this vowel in line with the phonology of the dialect. A closer examination of the results reveals that for Jaffa refugees living in Gaza, this is not entirely the case.

\section{(AH) results}

Based on the conditioning environments mentioned above for this variable, as a first step in the analysis all tokens of the feminine marker were coded for their preceding phonological environment. Our examination of this feature confirms the findings in earlier research with respect to phonological environments that condition raising, with the raising of the feminine marker blocked when following emphatic, pharyngeal, and glottal consonants. Following $/ r /$, raising was also blocked unless there was an /i/ or /i:/ in the preceding syllable (Al-Wer 2007: 68; Levin 1994: 44-45).

Because of this, those tokens of the feminine marker that occurred in situations where the preceding phonological environment blocked raising were excluded from the analysis, since no variation is attested in this environment. After excluding tokens that do not meet the conditions for potential raising, the sample contains 825 tokens of the feminine marker that occur in a phonological environment conducive to raising. Examples of the variability present in the data include:

- [yazza] vs [yazze] - 'Gaza'

- [kbi:ra] vs [kbi:re] - 'big' (fem.)

- [maglu:ba] vs [maglu:be] - 'Maqlu:ba' (a traditional food dish)

- [hilwa] vs [hilwe] - 'pretty' (fem.)

Our statistical analysis suggests that in the sample both Community and Year of Birth emerge as factors significant in determining variation in the data. These results are provided in Table 7 and Table 8.

Within the speech of Jaffa speakers, the data exhibit no true variation. These Jaffa speakers raise the feminine marker in line with the phonology of their dialect, as would be expected. This finding confirms that for these speakers $(\mathrm{AH})$ is not a true variable. Yet, some potential exceptions from the data collected in Jaffa should be highlighted. We argue that these apparent 
Table 7: Realization of (AH) in the speech of Jaffa residents and refugees of Jaffa heritage living in Gaza City correlated with Community $\left(\mathrm{R}^{2}=0.559\right.$; $\left.\mathrm{p}=1.85 \mathrm{e}-89\right)$

\begin{tabular}{lrrr}
\hline Community & \%[a] & Logodds & Tokens \\
\hline Gaza & 80 & 1.951 & 579 \\
Jaffa & 8 & -1.951 & 246 \\
\hline
\end{tabular}

Table 8: Realization of $(\mathrm{AH})$ in the speech of Jaffa residents and refugees of Jaffa heritage living in Gaza City correlated with Year of Birth $\left(R^{2}=0.559 ; p=1.8 e-09\right)$

\begin{tabular}{lcrr}
\hline Year of Birth & \%[a] & Logodds & Tokens \\
\hline Before 1948 & 38 & -0.816 & 240 \\
$1948-1973$ & 64 & 0.152 & 254 \\
1974 and after & 69 & 0.664 & 331 \\
\hline
\end{tabular}

exceptions reflect ongoing processes of nativization into the phonology of the Jaffa dialect, which result in examples like those presented below:

- n-na:s'sa 'Nazareth'

- Sans'urijja 'racism'

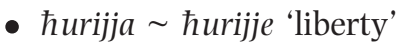

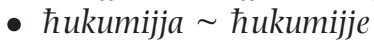
'governmental' (no raising, despite a historical /i/ in a preceding syllable)

(no raising, a word adapted from Standard Arabic)

(variable production between [a] and [e])

(variable production between [a] and [e])

Gaza speakers, regardless of other factors, show a strong tendency towards non-raising of this morpheme in their speech. This finding is in line with what Cotter (2013) reported, namely that the indigenous dialect of Gaza City does not raise this vowel and Jaffa refugees are converging towards local Gaza norms for this variable. The oldest generation of Gaza speakers shows the greatest tendency towards using a raised variant of the feminine marker, but for them this is not true vowel raising. Rather, they maintain a feature native to their traditional Jaffa dialect (Al-Wer 2007; Shahin 2007). Within the middle generation of the sample, there is now a tendency towards the lowering of the Jaffan [e] realization in the direction of what we call the unraised Gazan [a] variant (Cotter 2013). The only exception to this comes from a single speaker, Sabeer (born in 1960), who does exhibit some use of the raised variant [e] in his speech. However, Sabeer self-reports as being bi-dialectal, and notes at the end of the interview that his traditional Jaffa dialect is one that is primarily reserved for interactions with other family members, stating that he speaks differently fi f-fa:ris 'in the street.' 
Sabeer's linguistic production and his bi-dialectalism reflect a linguistic state which, of course, is not unique to Arabic or the Middle East. Mesthrie (2007: 152) discusses the conundrum faced by (mostly monolingual) Indian South Africans when contemplating travel to (multilingual) India. While Mesthrie was referring to cases of language shift, we argue that an analogy may be drawn with dialect shift. The Palestinian case differs from the Indian-South African one also in its much more confined geographical span. However, the isolation in which the Gaza community has found itself, especially since 1967 and even more so in the last decade, intensifies this connection despite the short distance between the Jaffa dialect's place of origin and the Gaza Strip. ${ }^{7}$ We will return to the Palestine-South Africa analogy later in this analysis.

Sabeer attests that his native Jaffa dialect is one which he associates with notions of 'home' or 'family,' contrasting it with a variety whose domain is located outside the home and in the wider community of Gaza City. We can interpret this association with the idea of indexicality (Eckert 2008; Silverstein 2003), where his native Jaffa dialect points to more intimate associations. Although Sabeer does not elaborate on the particulars of this other variety, it is presumed to be one more in line with the traditional dialect of Gaza City as it is today (Cotter 2013).

The youngest Gaza speakers show a reversal of the trends witnessed in the earlier generations of speakers in the sample, now strongly favoring the unraised [a] realization of the feminine marker. This tendency towards the loss of the raised [e] realization appears to be a direct result of contact with speakers of other Arabic dialects. For the case of the final variable we examine in this study, we again see Gaza speakers diverging from the traditional Jaffa dialect. However, we argue that the high social salience of the variable discussed below has forced a recontextualization of this feature, tying it to wider issues of identity.

\section{THE UVULAR STOP (Q)}

\section{History of the variable}

We now turn to the variable $(\mathrm{Q})$, which is perhaps the most widely examined linguistic feature in sociolinguistic studies of Arabic (e.g. Abd El-Jawad 1981, 1987; Al-Wer 2007; Al-Wer and Herin 2011; Hachimi 2007, 2012; Haeri 1997; Holes 1983). Versteegh describes the diachrony of this phoneme as having once been $/ \mathrm{g} /$, the voiced counterpart of the voiceless $/ \mathrm{k} /$. This voiced realization is still a prominent feature of Bedouin dialects of Arabic and is in line with the early Arabic grammarian Sibawayhi's classification of /q/ as madzhu:ra, the Arabic equivalent of 'voiced' (Versteegh 2001: 21, 89). Al-Jallad (2015) argues that there is actually no evidence of a voiced velar representing /q/ in pre-Islamic material or in the transcriptions of Arabic from the first Islamic century, often represented in Greek orthography. Rather, it is likely that as in other Semitic languages, the /q/ had evolved from an ejective 
(glottalized) velar, unmarked for voicing. He also notes (Ahmad Al-Jallad personal communication, 2 January 2015) that madzhu:ra in this context may imply some sort of voiced uvular consonant [G], but not a velar [g]. We maintain that Al-Jallad's reconstruction is more consistent both with the recent findings reported in his 2015 paper and with recent scholarship in comparative Semitic linguistics.

In urban dialects of the Levant, /q/ is typically realized as a glottal stop [?], with rural and Bedouin dialects often realizing this phoneme as [k] and [g], respectively. Al-Jallad (personal communication, 2 January 2015) notes that it is in fact plausible to assume that this contemporary glottal realization is a relic of the old glottalized velar, i.e. " $k$ ' > ?. As was noted above for the case of the feminine marker, however, these types of classifications provided by Cadora (1992) are not set in stone. The dialect of Amman represents a case in point, with $(Q)$ being realized variably between [g] and [?] (Al-Wer 2007; Versteegh 2001: 153). The expansion of the major regional capitals has aided in creating a situation wherein the dialects of the countryside are being replaced by those of the major cities, which in turn helps to form regional linguistic standards that run counter to the notion of 'standard' proposed in earlier works on diglossia in the Arab world (Ferguson 1959; Haeri 1997, 2000; Versteegh 2001: 153). These earlier works have treated the variety known as Modern Standard Arabic (or in its older manifestation, Classical Arabic) as the standard to which educated Arabic speakers aspire in their naturally occurring speech. However, as Haeri (2000) points out, based on Ibrahim (1986), 'Standard Arabic' is not naturally spoken or acquired by anyone in the Arabic speaking world, including the educated upper class. In every Arab speech community there is a local standard, often an urban one, which is based on some vernacular. This has created a situation in which different standards exist across different communities.

In dialects of Palestinian Arabic, the following four primary variants of the uvular stop /q/ have been attested (Shahin 2007: 527):

- $[\mathrm{k}]$ - voiceless velar stop

- [?] - glottal stop

- $[\mathrm{g}]$ - voiced velar stop

- [q] - voiceless uvular stop

In addition to the four realizations above, a fifth is present in some Palestinian dialects, where, "pharyngealized q is realized between a velar and uvular (transcribed as $\mathrm{k}\left[\mathrm{k}^{\mathrm{c}}\right]$ )' (Shahin 2007: 527). The uvular stop [q] was once a prominent feature in the dialect of Nablus in the northern West Bank, but has since given way to the [?] variant (Abd El-Jawad 1987: 361). The voiceless velar stop $[\mathrm{k}]$ is attested in rural and village dialects across historic Palestine. The glottal stop [?] is the prominent dialectal realization for /q/ in many of Palestine's urban centers including Jerusalem, present day Nablus, Jaffa, and Ramallah (which traditionally had [k]) (Abd El-Jawad 1987; Horesh 2000; Rosenhouse 2007; Shahin 2007). The voiced velar stop, [g], is a dialect 
feature that is most prominent in the Bedouin dialects of Palestine, particularly in the Nagab Desert region and the village dialects of the southern West Bank (Cleveland 1967; Palva 1984; Shahin 2007; Shawarbah 2012). Finally, the conservative voiceless uvular variant [q] is known to be preserved primarily by members of rural Druze communities in the Galilee and Mt. Carmel regions of northern Palestine (Blanc 1953: 68-69).

For the purposes of our study, the earliest source on the dialect of Gaza City notes the glottal [?] variant as the prominent realization of /q/ in the dialect (Bergsträßer 1915). However, later work by Salonen (1979, 1980) suggests that voiced velar $[\mathrm{g}]$ has become the predominant realization for $/ \mathrm{q} /$, presumably as a result of dialect contact with neighboring Bedouin tribes, all of which feature the [g] realization of /q/ in their dialects (de Jong 2000). This is confirmed by Barnea's (1973) texts and, as we note below, Cotter's (in press) work which shows widespread use of the $[\mathrm{g}]$ realization of $/ \mathrm{q} /$.

Al-Wer and Herin (2011) have made the important point that in a number of studies of Arabic sociolinguistics (Q) has been misidentified as a variable in situations where no true variation takes place. Damascus is cited as a primary example in this respect, a dialect which features [?] as its standard dialectal realization of /q/. While the true voiceless uvular [q] does occur in Damascus, as Al-Wer and Herin note, it is confined to lexical items from Standard Arabic or instances of extremely formal speech. The lack of true variation between [?] and [q] in Damascus creates a situation in which /q/ is not variable in the dialect, despite being labeled as such in previous studies. They offer Beirut and Jerusalem as further examples of this point, wherein /q/ has been misidentified as a variable in situations where no real variation occurs (Al-Wer and Herin 2011: 60-61).

From a variationist sociolinguistic perspective, the fact that discrete dialects show variation for a feature across speech communities is not sufficient for a determination that the feature in question is variable. What makes a variable a variable is the existence of intra-speaker and/or inter-speaker variation within the same speech community. Consider the following statement from Weinreich, Labov and Herzog (1968: 101): 'The key to a rational conception of language change - indeed, of language itself - is the possibility of describing orderly differentiation in a language serving a community.' For $(Q)$ this is rare, although, as recent work suggests, in a place with a tumultuous history of population changes such as Gaza, the emergence of $(Q)$ as a true sociolinguistic variable is unsurprising.

Cotter (in press) shows quite clearly that $(Q)$ has emerged as a variable in Gaza City and, in the speech of indigenous Gazans, male speakers overwhelmingly realize $(\mathrm{Q})$ as a voiced velar [g] (Table 9). Female speakers, in subtle contrast to their male counterparts, have more limitedly adopted the glottal [?] realization of $(\mathrm{Q})$. However, in the speech of female indigenous Gazans the adoption of [?] for (Q) is only evidenced in 24 percent of the tokens analyzed. 
Table 9: Realization of $(Q)$ in the speech of indigenous Gazans in Gaza City correlated with Gender $\left(\mathrm{R}^{2}=0.473 ; \mathrm{p}=2.54 \mathrm{e}-29\right)$ (from Cotter in press)

\begin{tabular}{lrcrr}
\hline Gender & $\%[?]$ & $\%[\mathrm{~g}]$ & Logodds & Tokens \\
\hline Female & 24 & 76 & 1.437 & 186 \\
Male & 5 & 95 & -1.437 & 191 \\
\hline
\end{tabular}

\section{(Q) results}

Within the subset of data collected from Gaza speakers, (Q) has emerged as a sociolinguistic variable, showing a statistically significant correlation with gender, with respect to variation between the [g] and [?] realizations of this phoneme. There is some indication that age might be a contributing factor as well, although our model did not find age to be statistically significant. Contrastively, in the speech of Jaffa speakers /q/ is not a true variable, being categorically realized as [?], in line with the traditional urban dialect of Jaffa (Horesh 2000; Shahin 2007). The only exceptions to this categorical realization can be found in certain lexical items, which may show variability based on their incomplete nativization into the lexicon of the dialect. These types of words are all either borrowings from formal registers such as Standard Arabic or place names. Some examples of these exceptions can be seen in:

- $k^{\text {S}}$ awmijja - 'nationalism'

- Sari:qa - 'deep-rooted'

- $k^{\zeta}$ alansawe - (toponym)

When examining the data from Gaza speakers it is possible to see a clear intrusion of the traditional Gaza [g] (Barnea 1973; Cotter in press; Salonen 1979, 1980). However, this has not resulted in the complete displacement of the traditional Jaffan [?]. Instead, for Gaza speakers, (Q) appears to be shifting, with the realization of this phoneme splitting along gender lines.

As Table 10 shows, female speakers of Jaffan heritage show the highest likelihood of realizing $(Q)$ as the traditional Jaffan [?], with the glottal realization occurring in 96 percent of the tokens analyzed. Male Jaffan speakers in the sample, in contrast, have overwhelmingly adopted the voiced velar $[\mathrm{g}]$ in 74 percent of the tokens in our corpus. The adoption of the voiced velar $[\mathrm{g}]$ is in line with the wider tendency in the dialect of Gaza City, which cuts across gender lines, to realize this variable as a voiced velar. We argue that the high degree of maintenance of the Jaffan [?] among female speakers across generations suggests that $(Q)$ is doing identity-related work in Gaza City, given that the speech of male speakers has changed so dramatically. We return to the relationship between linguistic production and identity in Gaza City in our discussion.

The tendency for female speakers to spearhead the realization of $(Q)$ as [?] has been noted in numerous other studies of Arabic sociolinguistics. It has 
Table 10: Realization of $(Q)$ in the speech of Jaffa refugees living in Gaza City correlated with Gender $\left(\mathrm{R}^{2}=0.473 ; \mathrm{p}=2.54 \mathrm{e}-29\right)$ (from Cotter in press)

\begin{tabular}{lcrrr}
\hline Gender & $\%[?]$ & $\%[g]$ & Logodds & Tokens \\
\hline Female & 96 & 4 & 1.437 & 82 \\
Male & 26 & 74 & -1.437 & 116 \\
\hline
\end{tabular}

been documented in the Arabic of Nablus in Palestine (Abd El-Jawad 1987), Amman in Jordan (Abd El-Jawad 1981; Al-Wer 2007), and the Egyptian capital of Cairo (Haeri 1997), ${ }^{8}$ as well as others. In the Levant, [?] represents a supralocal variant of (Q) (Al-Wer 1997) and prior work on this variable has shown that female speakers tend to opt for these supralocal variants in their speech, while male speakers opt for more localized variants (see Milroy et al. 1994 for a parallel case in northeast England). The data collected from Jaffa refugees in Gaza are no exception to this. Despite being relative newcomers (in sociolinguistic terms) to Gaza City, male Jaffa refugees show extremely high rates of usage of this variant (Cotter in press). Based on the results presented above, the situation of $(Q)$ appears to resemble a straightforward case of dialect contact and change. However, as we argue below, the high social salience of (Q) has created a situation in which its variants act as identity markers for Jaffan refugees in Gaza City.

\section{DISCUSSION AND CONCLUSION}

The results of our study indicate that for the three variables under investigation the speech of Jaffa refugees has largely diverged from their traditional dialect, converging towards local norms in Gaza City. Lenition of the voiced pharyngeal fricative (£), which is widespread in the Jaffa dialect as an outcome of contact with Modern Hebrew (Horesh 2014), proves to be much less frequent in the speech of Jaffa refugees, in line with the local tendency in Gaza City to retain the pharyngeal fricative. In addition, raised $(\mathrm{AH})-[\mathrm{e}]-\mathrm{a}$ hallmark feature of the Jaffa dialect, has almost disappeared completely in the speech of young Jaffa refugees in Gaza, showing a strong tendency for convergence towards the localized unraised [a] variant. Finally, for $(\mathrm{Q})$, Jaffa refugees have again diverged from the traditional Jaffan glottal [?] realization of this phoneme, but this divergence is stratified along gender lines. In this respect female speakers show a strong tendency to retain the traditional Jaffan glottal realization of $(\mathrm{Q})$ while male speakers have converged towards the local Gazan $[\mathrm{g}]$ realization.

However, as we have noted above, the [?] variant of (Q) represents a supralocal variant and female speakers show a clear tendency to opt for these variants across the Levant (Al-Wer 1997, 2007). In another analogy to the South African sociolinguistic situation - this time from the post-Apartheid era 
- Mesthrie (2010: 28) refers to the linguistic 'acculturation to the White norm' for the English vowel in Goose. He concludes that Black females form the social group that is the most prone to this acculturation. This appears to be not merely another case of females leading a phonological change. These speakers stood out among females and males of various South African ethnic groups, and their linguistic innovation has as its target a sort of supralocal standard similar to the supralocal glottal stop variant of $(Q)$ which we report about here. The tendencies of female speakers could also be seen to reify the indexicality of this variant with notions of 'femininity' or 'urbanness,' a point raised by speakers themselves during fieldwork in the Gaza Strip, and the oft-reported stigmatic interpretation of the glottal variant when used by male speakers or in non-urban communities (Al-Wer 2014; Eckert 2008; Hachimi 2012; Silverstein 2003).

Having analyzed the three variables presented in this study, it has become clear that while all of them deserve close scrutiny and further investigation, (Q) is the variable that bears the broadest general implications. (؟) and (AH) both appear to be heading in directions typical of changes in progress. Yet $(\mathrm{Q})$ is emerging as a much more salient variable that may illustrate processes related to identity that are relevant cross-linguistically.

As we have mentioned above, in most other dialects it is not worthy of the label 'variable' at all. Furthermore, it is a variable that has a very clear supralocal variant, which can have implications for other, much more widespread dialects, as well as to sociolinguistic theory. For instance, in many studies of Arabic dialects, a glottal realization of (Q) by female speakers in non-urban communities is often dismissed as an imitation of urban speech or a desire to sound 'feminine' or 'delicate.' These kinds of characterizations are devoid of any theoretical considerations and should be modified in a manner that views them as a particular manifestation of the well-known trend for women to be leaders of linguistic innovation. A broader theoretical contribution that phenomena such as this can make to sociolinguistics at-large is in the coupling of the 'women as linguistic innovators' notion with a more nuanced birds-eye view of the context of one speech community vis-à-vis other speech communities who speak other, yet related varieties of their language. Finally, it is the one variable in this study that attracts the most social awareness from speakers. (؟) and (AH) appear to still be flying under the radar for most (if not all) speakers. But members of the community time and time again express their sometimes quite emotional reactions to people using this or that variant of $(Q)$.

Perhaps the gender distinction, which is quite robust for this variable, is the key to explaining why this is so. People are aware of all sorts of gender-conforming and gender non-conforming behaviors, and linguistic behaviors that fall along gender lines are not an exception. We see this in many other speech communities in which female speakers are innovators of linguistic change. In the Gaza/Jaffa case, as in the South African case reported 
by Mesthrie, additional political and societal factors enter into the mix as well. In our final remarks, therefore, we will pay closer attention to the $(Q)$ variable than to the other two.

We argue that, for Gaza speakers, $(\mathrm{Q})$ has been recontextualized as a result of contact borne out of rapid social, cultural, and political change into a marker of community identity, but one that has been realized sociolinguistically along gender lines. As we have previously alluded, conceptualizations of meaning as they relate to (Q) are not inherently uniform. (Q) may do different kinds of identity-related work and take on different social meanings at various levels within a given community. The result is a situation in which identity operates at different levels and in varied 'markets' for Jaffan refugees in Gaza City, located not only at an event/ interaction based level, but also at more meta-pragmatic or meta-cultural levels (Agha 2007; Eckert 2000; Wortham 2006).

The linguistic practices of male Jaffa refugees in converging towards localized Gaza norms for (Q) (Cotter in press) work to locate them as part of a wider Gaza community, one which is made up of Palestinians from varied geographic backgrounds. These practices, along with the reality that many refugees in Gaza are of dialect backgrounds that have [g] as their traditional realization of $(Q)$, also works to mitigate the potential associations between specific variants of $(\mathrm{Q})$ and 'refugee speech' given the high social salience of this linguistic feature. The link between language and identity in this sense further reifies the reality of the social, economic, and political situation of the Gaza Strip, a reality that is drastically different from that of many other Palestinian communities throughout the Middle East.

Simultaneously, for female Gaza speakers and their interlocutors, their linguistic practices make it possible for them to maintain a historically grounded notion of community located outside of Gaza City. In this sense, the use of the [?] variant of $(\mathrm{Q})$ does work to locate female speakers as ja:fa:wijje 'Jaffan' within a diverse linguistic environment. This aids in maintaining Jaffan identity over a period of time when the language of male speakers in this community seems to be more readily changing (see Hoffman 2008 for a related case in Morocco). Although the glottal realization of $(\mathrm{Q})$ is supralocal in the region, if this were merely a case of female speakers leading phonological change, in line with wider regional trends, we would expect indigenous Gaza women themselves to have more readily adopted the glottal realization of $(Q)$. The fact that it has not been more readily adopted among indigenous Gaza speakers (see Cotter in press), we argue, lends support to the idea that the linguistic practices of Jaffan refugees are more intimately tied to identity in this specific context. At a more macro level, the practices of female speakers with respect to $(\mathrm{Q})$ simultaneously situates them as part of the wider Palestinian community, given the prominent status of this variant throughout the Levant and in Palestine's urban centers, regardless of the actual physical or geographic location of the speakers themselves. 
The connection between linguistic production and different forms of identity work that we have proposed in relation to these Gaza speakers finds grounding in the work of other communities, notably the Indian South African community (Mesthrie 2007). As Mesthrie notes regarding the South African situation,

The gains of becoming bilingual in English were thus 'outward' in terms of economic mobility and social integration within the broader South African society; while the subsequent impulse towards shift was more 'inward' in terms of new identity formation as a close-knit Indian South African minority. (2007: 151)

The Gaza case reflects a similar situation, but one which is intimately tied to processes of dialect contact that comes as a result of political conflict as opposed to bilingualism. The production we see in the Gaza speakers of our sample provides an example of how both inter-speaker and intra-speaker production can do identity work that looks both outward towards a wider more macro-oriented community while simultaneously looking inward as well.

Bucholtz and Hall have argued that linguistic processes like that which we have described can work to preserve community identity in situations of intense social or cultural change, while also allowing individuals to locate themselves within multiple identity frames at a given moment (Bucholtz and Hall 2004: 383). The Palestinian community represents a clear case of intense social and cultural change that continues to evolve as the result of seven decades of protracted political conflict. This has dispersed a once geographically localized community across the entirety of the Middle East and has fractured, in every sense of the word, many aspects of Palestinian life and community identity. What was once simply Palestinian can now be divided and compartmentalized into refugee, Gazan, West Banker, tama:nija w-ParbaGi:n (lit. "48;' refers to Palestinian citizens of Israel, who as a group have shifted to this status in 1948), etc. Naturally, language exists as part of this social and cultural milieu and, as the results of this study show, continues to evolve alongside and as a result of the changes taking place at various levels within the Palestinian community. As our analysis suggests, dialect contact in this sense has laid the foundation for the refashioning of one of Arabic's most socially salient linguistic features into a marker of identity that locates speakers as members of communities both locally and across geographic, political, and social borders.

\section{NOTES}

1. We would like to thank Becky Childs and Mary-Caitlyn Valentinsson for their insightful comments and suggestions for improvement on earlier drafts of this work. We extend additional thanks to Enam Al-Wer for her continual support, advice, and encouragement, as well as to Ahmad Al-Jallad and Benjamin Hary 
for offering advice and further reading material. In addition we extend our thanks to the editors and three anonymous reviewers whose comments have further helped to improve the article over the course of revision. Any remaining errors are, of course, our own. Finally, we would like to thank those members of the Jaffa and Gaza speech communities who welcomed us into their homes and shared their lives with us over the course of the research. You deserve far more than a journal article but we hope that this contribution does justice to the reality that you shared with us.

2. http://www.unrwa.org/where-we-work (accessed 21 June 2015). Some Palestinian refugees do not formally register with the United Nations, so the percentage of the Gaza population that is of a refugee background is higher than the numbers reported by the UNRWA (United Nations Relief and Works Agency for Palestinian Refugees in the Near East).

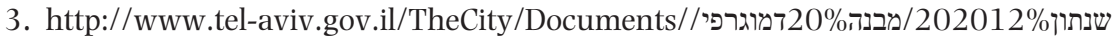
הסבר 20\%.pdf (accessed 3 February 2014).

4. Also note the degeminated [1]. Variable loss of gemination is believed to be another consequence of Arabic-Hebrew contact.

5. Note that ' $(\mathrm{AH})$ ' is a mnemonic based on the history of Arabic and the glyph: used in Standard Arabic to denote the feminine ending. It does not imply the synchronic presence of a $/ \mathrm{h} /$ sound in the varieties of Arabic discussed here.

6. The reason this variant is considered 'raised' is that in Standard Arabic the feminine ending is invariantly $-a$.

7. Schilling-Estes (2002) explains the intricacies of isolation and its effect on speech patterns across generations in two Native American communities. These cases are not as extreme in their isolation as the Gaza Strip, but the principles are similar.

8. Cairene Arabic has undergone the shift $* q>$ ?. However, $[\mathrm{q}]$ is re-emerging as a possible variant in certain innovative lexical items, which entered the dialect long after this shift occurred (Haeri 1997: ch. 4).

\section{REFERENCES}

Abd El-Jawad, Hassan. 1981. Lexical and phonological variation in spoken Arabic in Amman. Unpublished PhD dissertation. Philadelphia, Pennsylvania: University of Pennsylvania.

Abd El-Jawad, Hassan. 1987. Cross dialectal variation in Arabic: Competing prestigious forms.

Language in Society 16: 359-367.

Agha, Asif. 2007. Language and Social Relations. Cambridge, U.K.: Cambridge University Press. Al-Jallad, Ahmad. 2015. Graeco-Arabica I: The Southern Levant. In Françoise BriquelChatonnet, Muriel Debi and Laila Nehm (eds.) Le contexte de naissance de l'écriture arabe: Écrit et écritures araméennes et arabes au 1er millénaire après J.-C., Actes du colloque international du projet ANR Syrab. Louvain, Belgium: Peeters (Orientalia Lovaniensa Analecta). 1-60.

Al-Wer, Enam. 1997. Arabic between reality and ideology. International Journal of Applied Linguistics 7: 251-265.

Al-Wer, Enam. 2002. Jordanian and Palestinian dialects in contact: Vowel raising in Amman.

In Mari C. Jones and Edith Esch (ed.) Language Change: The Interplay of Internal, External and Extra-linguistic Factors. Berlin, Germany: Mouton de Gruyter. 63-79. 
Al-Wer, Enam. 2007. The formation of the dialect of Amman: From chaos to order. In Catherine Miller, Enam Al-Wer, Dominique Caubet and Janet Watson (eds.) Arabic in the City. New York: Routledge. 55-76.

Al-Wer, Enam. 2014. The Middle East and North Africa. In Susan Ehrlich, Miriam Meyerhoff and Janet Holmes (eds.) The Handbook of Language, Gender, and Sexuality (2nd edition). Oxford, U.K.: Wiley-Blackwell. 396-411.

Al-Wer, Enam and Bruno Herin. 2011. The lifecycle of qaf in Jordan. Langage et société 138: $59-76$.

Barnea, Aharon. 1973. Gaza Stadt. Last accessed 13 July 2015 at http://www.semarch. uni-hd.de/

Barnea, Aharon. 1975. Reference to time, space and other types of quantification in the city dialect of Gaza. Afroasiatic Linguistics 2: 51-60.

Bergsträßer, Gotthelf. 1915. Sprachatlas von Syrien und Palästina. Leipzig, Germany: Hinrichs.

Blanc, Haim. 1953. Studies in North Palestinian Arabic: Linguistic Inquiries among the Druzes of Western Galilee and Mt. Carmel. Jerusalem, Israel: Israel Oriental Society.

Bucholtz, Mary and Kira Hall. 2004. Language and identity. In Alessandro Duranti (ed.) A Companion to Linguistic Anthropology. Cambridge, U.K.: Cambridge University Press. 369-394.

Cadora, F. J. 1992. Bedouin, Village, and Urban Arabic: An Ecolinguistic Study (Studies in Semitic Languages and Linguistics 18). Leiden, The Netherlands: Brill.

Cleveland, Ray L. 1967. Notes on an Arabic dialect of southern Palestine. Bulletin of the School of Oriental and African Studies 185: 43-57.

Cotter, William. 2013. Dialect contact and change in Gaza City. Unpublished MA dissertation. Colchester, U.K.: University of Essex.

Cotter, William. In press. (q) as a sociolinguistic variable in the Arabic of Gaza City. In Youssef Haddad and Eric Potsdam (eds.) Perspectives on Arabic Linguistics XXVIII. Amsterdam, The Netherlands: John Benjamins.

De Jong, Rudolf E. 2000. A Grammar of the Bedouin Dialects of the Northern Sinai Littoral: Bridging the Linguistic Gap between the Eastern and Western Arab World. Leiden, The Netherlands: Brill.

Eckert, Penelope. 2000. Linguistic Variation as Social Practice: The Linguistic Construction of Identity in Belten High. Malden, Massachusetts: Blackwell Publishers.

Eckert, Penelope. 2008. Variation and the indexical field. Journal of Sociolinguistics 12: $453-476$.

Ferguson, Charles A. 1959. Diglossia. Word 15: 325-340.

Fishman, Joshua A. (ed.). 1999. The Handbook of Language and Ethnic Identity. New York: Oxford University Press.

Grotzfeld, Heinz. 1980. Das syrisch-palästinesische Arabisch. In Wolfdietrich Fischer and Otto Jastrow (eds.) Handbuch der arabische Dialekte. Wiesbaden, Germany: Otto Harrassowitz. 174-190.

Hachimi, Atiqa. 2007. Becoming Casablancan: Fessis in Casablanca as a case study. In Catherine Miller, Enam Al-Wer, Dominique Caubet and Janet C. E. Watson (eds.) Arabic in the City: Issues in Dialect Contact and Language Variation. New York: Routledge. 97-122.

Hachimi, Atiqa. 2012. The urban and the urbane: Identities, language ideologies, and Arabic dialects in Morocco. Language in Society 41: 321-341.

Haeri, Niloofar. 1997. The Sociolinguistic Market of Cairo: Gender, Class and Education. London/ New York: Kegan Paul International. 
Haeri, Niloofar. 2000. Form and ideology: Arabic sociolinguistics and beyond. Annual Review of Anthropology 29: 61-87.

Hawker, Nancy. 2013. Palestinian-Israeli Contact and Linguistic Practices. New York: Routledge. Henkin-Roitfarb, Roni. 2011. Hebrew and Arabic in asymmetric contact in Israel. Lodz Papers in Pragmatics 7: 61-100. doi: 10.2478/v10016-011-0004-7

Hoffman, Katherine. 2008. We Share Walls: Language, Land, and Gender in Berber Morocco. Oxford, U.K.: Wiley-Blackwell.

Holes, Clive. 1983. Patterns of communal language variation in Bahrain. Language in Society 12: $433-457$.

Horesh, Uri. 2000. Toward a phonemic and phonetic assessment of Jaffa Arabic: Is it a typical urban Palestinian dialect? In Manwel Mifsud (ed.) Proceedings of the Third International Conference of AIDA: Association Internationale de Dialectologie Arabe. Paris, France: AIDA / Malta: Salesian Press. 15-20.

Horesh, Uri. 2014. Phonological outcomes of language contact in the Palestinian Arabic dialect of Jaffa. Unpublished PhD thesis. Colchester, U.K.: University of Essex.

Ibrahim, Muhammad. 1986. Standard and prestige language: A problem in Arabic sociolinguistics. Anthropological Linguistics 28: 115-126.

Johnson, Daniel Ezra. 2009. Getting off the GoldVarb standard: Introducing Rbrul for mixedeffects variable rule analysis. Language and Linguistics Compass 3: 359-383.

Lentin, Jérôme. 2007. Damascus Arabic. In Kees Versteegh (ed.) Encyclopedia of Arabic Language and Linguistics. Leiden, The Netherlands: Brill. 546-555.

Levin, Aryeh. 1994. A Grammar of the Arabic Dialect of Jerusalem [in Hebrew]. Jerusalem, Israel: Magnes Press, the Hebrew University.

LeVine, Mark. 2005. Overthrowing Geography: Jaffa, Tel-Aviv, and the Struggle for Palestine 1880-1948. Berkeley, California: University of California Press.

Mesthrie, Rajend. 2007. Language shift, cultural change and identity retention: Indian South Africans in the 1960s and beyond. South African Historical Journal 57: 134-152. doi: $10.1080 / 02582470709464713$

Mesthrie, Rajend. 2010. Socio-phonetics and social change: Deracialisation of the Goose vowel in South African English. Journal of Sociolinguistics 14: 3-33.

Milroy, James, Lesley Milroy, Sue Hartley and David Walshaw. 1994. Glottal stops and Tyneside glottalization: Competing patterns of variation and change in British English. Language Variation and Change 6: 327-357.

Morris, Benny. 2008. 1948: A History of the First Arab-Israeli War. New Haven, Connecticut: Yale University Press.

Naïm, Samia. 2007. Beirut Arabic. In Kees Versteegh (ed.) Encyclopedia of Arabic Language and Linguistics. Leiden, The Netherlands: Brill. 274-286.

Palva, Heikki. 1984. A General Classification of the Arabic Dialects Spoken in Palestine and Transjordan. Helsinki, Finland: Finnish Oriental Society.

Pappé, Ilan. 2006. The Ethnic Cleansing of Palestine. Oxford, U.K.: Oneworld.

Rosenhouse, Judith. 2007. Jerusalem Arabic. In: Kees Versteegh (ed.) Encyclopedia of Arabic Language and Linguistics. Leiden, The Netherlands: Brill. 481-493.

Salonen, Erkki. 1979. Zum arabischen Dialekt von Gaza, Teil I. Helsinki, Finland: Finnish Oriental Society.

Salonen, Erkki. 1980. Zum arabischen Dialekt von Gaza, Teil II. Helsinki, Finland: Suomalainen Tiedeakatemia.

Schilling-Estes, Natalie. 2002. On the nature of isolated and post-isolated dialects: Innovation, variation, and differentiation. Journal of Sociolinguistics 6: 64-85.

(C) 2015 John Wiley \& Sons Ltd 
Shahin, Kimary. 2007. Palestinian Arabic. In Kees Versteegh (ed.) Encyclopedia of Arabic Language and Linguistics. Leiden, The Netherlands: Brill. 526-538.

Shawarbah, Musa. 2012. A Grammar of Negev Arabic: Comparative Studies, Texts, and Glossary in the Bedouin Dialect of the 'Azāzmih Tribe. Wiesbaden, Germany: Harrassowitz Verlag.

Silverstein, Michael. 2003. Indexical order and the dialectics of sociolinguistic life. Language and Communication 23: 193-229.

Versteegh, Kees. 2001. The Arabic Language. Edinburgh, U.K.: Edinburgh University Press.

Weinreich, Uriel, William Labov and Marvin I. Herzog. 1968. Empirical foundations for a theory of language change. In W. P. Lehmann and Yakov Malkiel (eds.) Directions for Historical Linguistics: A Symposium. Austin, Texas/London: University of Texas Press. 96-195.

Wexler, Paul. 1990. The Schizoid Nature of Modern Hebrew: A Slavic Language in Search of a Semitic Past. Wiesbaden, Germany: Otto Harrassowitz.

Woidich, Manfred. 2007. Cairo Arabic. In Kees Versteegh (ed.) Encyclopedia of Arabic Language and Linguistics. Leiden, The Netherlands: Brill. 323-333.

Wortham, Stanton. 2006. Learning Identity: The Joint Emergence of Social Identity and Academic Learning. Cambridge, U.K.: Cambridge University Press.

Zuckermann, Ghil'ad. 2003. Language Contact and Lexical Enrichment in Israeli Hebrew. New York: Palgrave Macmillan.

Address correspondence to:

William Cotter

School of Anthropology and Department of Linguistics

University of Arizona

1009 East South Campus Drive

Tucson

Arizona 85721

U.S.A.

williamcotter@email.arizona.edu 